\title{
PENGARUH GOOD CORPORATE GOVERNANCE, KEPEMILIKAN SAHAM PUBLIK DAN PROFITABILITAS TERHADAP TINGKAT PENGUNGKAPAN CORPORATE SOSIAL RESPONSIBILITY
}

\author{
Prisila Damayanti \\ Email: Prisild@ rocketmail.com \\ Program Studi Akuntansi Institut Bisnis dan Informatika Kosgoro 1957 \\ Hendi Prihanto \\ Email: hendiholden77@gmail.com \\ Program Studi Akuntansi Universitas Prof. Dr. Moestopo \\ Fairuzzaman \\ Email: prisild@rocketmail.com \\ Program Studi Akuntansi Institut Bisnis dan Informatika Kosgoro 1957
}

\begin{abstract}
ABSTRAK
Tujuan penelitian untuk mengetahui pengaruh good corporate Governance (ukuran kepemilikan institusional, saham publik) dan profitabilitas (Gross Profit Margin) terhadap pengungkapan CSR. Penelitian menggunakan data sekunder yang dikumpulkan dari perusahaan manufaktur periode 2016 sampai dengan 2018. Sampel diambil dengan menggunakan metode purposive sampling. Adapun data yang diperoleh bersumber pada data laporan tahunan Indonesia Capital Market Directory dan situs resmi BEI. Penelitian menggunakan analisis regresi berganda, adapun hasil penelitian menghasilkan bahwa komposisi dewan komisaris independen dan profitabilas berpengaruh positif terhadap pengungkapan CSR sedangkan kepemilikan institusional dan kepemilikan saham publik tidak berpengaruh terhadap pengungkapan CSR.
\end{abstract}

Kata kunci: Kepemilikan Institusional, Komisaris, Kepemilkan Saham Publik, Profitabilitas, CSR

ABSTRACT

The purpose of this research is to know the effect of good corporate governance, public share ownership and profitability on CSR disclosure. The study used secondary data collected from manufacturing companies for the period 2016 to 2018 . The sample was taken using the purposive sampling method. The data obtained is sourced from the Indonesia Capital Market Directory annual report and the IDX official website. The study used multiple regression analysis, while the results showed that the composition of the independent board of commissioners and profitability had a positive effect on CSR disclosure, while institutional ownership and public share ownership had no effect on CSR disclosure.

Keywords: Institutional Ownership, Commissioner, Public Share Ownership, Profitability, CSR

\section{PENDAHULUAN}

Laporan corporate sosial responsibility (CSR) telah dilaksanakan oleh berbagai perusahaan dan menjadi suatu praktik umum hal ini dilakukan oleh ribuan perusahaan diseluruh dunia dengan jumlah yang terus bertambah setiap tahunnya (Ernst \& Young dan Boston College Center for Corporate Citizenship, 2016). Berbagai faktor telah berkontribusi terhadap pengungkapan CSR diantaranya adalah praktik good governance. (Chau \& Gray, 2010)(Ezat \& El-Masry, 2008)(Khan et al., 2013). Dalam melaksanakan kegiatan bisnis suatu 
perusahaan disamping meninggalkan efek baik positif dapat pula meninggalkan dampak tidak baik atau negative kepada lingkungan sekitar sehingga perusahaan dituntut untuk dapat menjaga lingkungan dan menyeimbangkan pelaksanaan kegiatan operasional dengan meningkatkan taraf hidup masyakarat dan menjaga lingkungan agar lestari. Keberlangsungan hidup suatu perusahaan harus dijaga dengan cara menjaga kepentingan stakeholder. Konsep corporate sosial responsibility (CSR) telah menjadi perhatian negara-negara berkembang dimana CSR sdipandang untuk mengurangi kesenjangan tata kelola yang lemah atau kekurangan sumber daya sehingga dapat memberikan jasa layanan sosial yang memadai (Dartey-Baah \& Amponsah-Tawiah, 2011). Motivasi pelaksanaan program CSR dinegaranegara berkembang masih dalam tatanan Filantropi dimana CSR mencoba memberikan tanggung jawab atas dampak kegiatan perusahaan dan meningkatkan kegiatan yang bersifat positif dengan stakeholder dan saling menjaga kepentingan melalui kegiatan berupa menjaga lingkungan, konsumen, karyawan, komunitas, pemangku kepentingan dan para stakeholder lainnya. (Fonstaine, 2013). Penelitian CSR di negara Indonesia menjadi suatu hal yang penting mengingat semua sektor industri telah mengklaim telah melakukan kegiatan sosial dengan motivasi untuk meningkatkan kepercayaan masyarakat luas dalam upaya untuk perbaikan lingkungan. (Damayanty \& Djaddang, 2020)

Good Corporate Governance (GCG) merupakan sebuah aturan yang mengatur hubungan dengan pihak yang memiliki kepentingan untuk dapat menjaga keseimbangan antara hak dan kewajiban. GCG dapat mengatur agar suatu perusahaan dapat memberikan nilai tambah bagi semua stakeholder, dimana perusahaan bukan hanya sebatas fokus kepada kegiatan operasionalnya, tetapi perusahaan juga berada dalam suatu lingkungan sekitar, sehingga perusahaan juga harus menjaga lingkungan sekitar agar terjadi timbal balik antara perusahaan dan masyarakat. Tata Kelola perusahaan juga akan berpengaruh terhadap pemenuhan kewajiban pajak perusahaan. (Damayanty \& Putri, 2021). GCG telah mengarah sebagai suatu bentuk wadah yang telah mengakomodasi hubungan bisnis dengan lingkungan bisnis dan juga masyarakat. Peran corporate governance yang kurang kuat akan menyebabkan suatu perbuatan yang mengesampingkan kepentingan investor sehingga berdampak bagi pengembalian keuntungan yang diharapkan atas sumber daya yang diinvestasikan. (Mayasari, 2021)

Kepemilikan institusional menjadi alat untuk dapat dilakukan kegiatan pengawasan terhadap kinerja perusahaan sehingga dengan bertambah besarnya jumlah saham yang 
dimiliki oleh institusi akan menaikkan tingkat pengawasan kinerja termasuk pelaksanaan CSR dalam perusahaan dalam mengimplementasikan fungsi pengawasan tentunya diharapkan dapat menjamin kesejahteraan para pemengang saham. (Sandy et al., 2020). Perusahaan pada intinya harus memiliki susunan organisasi yang dapat mengontrol suatu proses kegiatan perusahaan yang harusnya dapat menghasilkan suatu citra yang positif didalam suatu masyarakat. Dewan komisaris independen merupakan dewan yang berada diluar perusahaan dimana dewan komisaris bersifat netral dan tidak dapat dipengaruhi oleh pihak manajemen yang akan melindungi stakeholder dalam upaya melakukan kegiatan CSR. (Jii, 2015). Dalam literatur sebelumnya juga memberikan bukti bahwa kepemilikan institusional, dewan komisaris independen dapat mendorong pengungkapan CSR (Chau \& Gray, 2010)(Khan et al., 2013)(Saleh et al., 2010).

Profitabilitas merupakan hasil pembagian antara laba dibanding dengan aktiva ataupun modal perusahaan atau dapat juga dikatakan suatu keberhasilan perusahaan dalam menghasilkan laba dimana kegiatan tersebut perusahaan menggunakan sumber daya aset yang dimiliki perusahaan Dimana semakin tinggi profitabilitas maka akan semakin tinggi pula pengungkapan CSR. (Hidayat, 2017). Para investor memiliki kepentingan terhadap profitabilitas dimana semakin bagus kinerja suatu perusahaan maka akan menaikan citra perusahaan yang akan berdampak terhadap keinginan para investor untuk menanamkan modalnya karena laba atau keuntungan perusahaan pada akhirnya akan diberikan Kembali kepada shareholder dalam bentuk dividen (Widjanarko \& Nurmelia, 2020). Beberapa penelitian terkait terhadap pengaruh kinerja perusahaan terhadap pengungkapan CSR telah dilakukan diantaranya. (Pyo \& Lee, 2013)(Maqbool \& Zameer, 2018)(Wahba \& Elsayed, 2015)

\section{METODE PENELITIAN}

\section{Design penelitian}

Penelitian ini termasuk dalam penelitian kuantitatif dengan mengunakan model kausalitas dimana model ini menguji variabel yang dapat merubah variabel lain atau yang tidak mengubah variabel. Sekaran dan Baugie (2017). Data yang dipergunakan dalam riset ini merupakan data sekunder yaitu pelaporan keuangan yang sudah diaudit yang dipublikasikan dari Pusat Referensi Pasar Modal (PRPM) BEI dan ICMD. Data dalam penelitian ini yang dikumpulkan berasal dari industry manufaktur yang terdaftar di Bursa 
Efek Indonesia pada periode tahun 2016 sampai dengan tahun 2018, terdiri 78 sampel. Riset ini digunakan metode multiple moderated regression analysis

\section{Pengukuran}

Dalam penelitian ini menggunakan pengukuran variabael independen dan dependen sebagai berikut:

\section{Tabel 1 Pengukuran}

\begin{tabular}{|c|c|c|}
\hline Variabel & Definisi Variabel & Pengukuran \\
\hline $\begin{array}{l}\text { Variabel Dependen } \\
\text { Tingkat Pengungkapan CSR }\end{array}$ & $\begin{array}{l}\text { Pengungkapan } \\
\text { tanggungjawab sosial } \\
\text { perusahaan terhadap } \\
\text { lingkungan dan masyarakat } \\
\text { sekitar }\end{array}$ & $\begin{array}{c}\text { CSRDI = Jumlah item } \\
\text { pengungkapan yang dipenuhi } \\
\text { dibagi Jumlah item yang } \\
\text { mungkin dipenuhi }\end{array}$ \\
\hline \multicolumn{3}{|l|}{ Variabel Independen } \\
\hline Good Corporate Governance & $\begin{array}{l}\text { Sebuah aturan yang } \\
\text { mengatur hubungan dengan } \\
\text { pihak yang memiliki } \\
\text { kepentingan untuk dapat } \\
\text { menjaga keseimbangan } \\
\text { antara hak dan kewajiban. }\end{array}$ & $\begin{array}{c}\mathrm{KI}=\text { Saham yang dimiliki } \\
\text { institusi dibagi Jumlah } \\
\text { saham yang beredar } \\
\text { DKI = Jumlah dewan } \\
\text { komisaris independen dibagi } \\
\text { total anggota dewan } \\
\text { komisaris }\end{array}$ \\
\hline $\begin{array}{l}\text { Komposisi Kepemilikan } \\
\text { Saham Publik }\end{array}$ & $\begin{array}{l}\text { Proporsi kepemilikan } \\
\text { saham yang dimiliki oleh } \\
\text { publik/masyarakat terhadap } \\
\text { saham perusahaan }\end{array}$ & $\begin{array}{c}\mathrm{KSP}=\text { Kepemilikan saham } \\
\text { publik dibagi saham yang } \\
\text { beredar }\end{array}$ \\
\hline Profitabilitas & $\begin{array}{l}\text { Kemampuan perusahaan } \\
\text { dalam menghasilkan laba } \\
\text { pada periode tertentu }\end{array}$ & $\begin{array}{c}\text { GPM = Penjualan laba bersih } \\
\text { dikurangi harga pokok } \\
\text { penjualan menghasilkan laba } \\
\text { kotor dibagi dengan } \\
\text { penjualan }\end{array}$ \\
\hline
\end{tabular}

Sumber: Data diolah

Analisis data menggunakan analisis regresi berganda, Adapun model data analisis dengan persamaan sebagai berikut:

$$
\text { CSRDI }=\beta 0+\beta 1 . K I+\beta 2 . D K I+\beta 3 . K S P+\beta 4 G P M+\varepsilon ́ \text { it }
$$

Keterangan: KI (Kepemilikan Institusional), DKI (Dewan Komisaris Independen), KSP (Kepemilikan Saham Publik), dan GPM (Gross Profit Margin).

\section{HASIL DAN PEMBAHASAN}

Hasil

Hasil pengujian mengunakan alat pengolahan data SPSS diperoleh hasil keseluruhan variabel memenuhi asumsi role of thumb yang ditetapkan dalam persyaratan asumsi klasik. 
Keseluruhan variabel yang diuji dengan distribusi mengunakan data sekunder meliputi uji deskriptif statistik, tidak terjadi permasalahan serius pada uji normalitas, multikolineritas dan heteroskedastisitas

\section{Uji Hipotesis}

Berdasarkan hasil analisis yang diolah pada model regresi yang meliputi variabel Independen dan Dependen dengan menggunakan SPSS versi 21 maka dihasilkan analisis regresi:

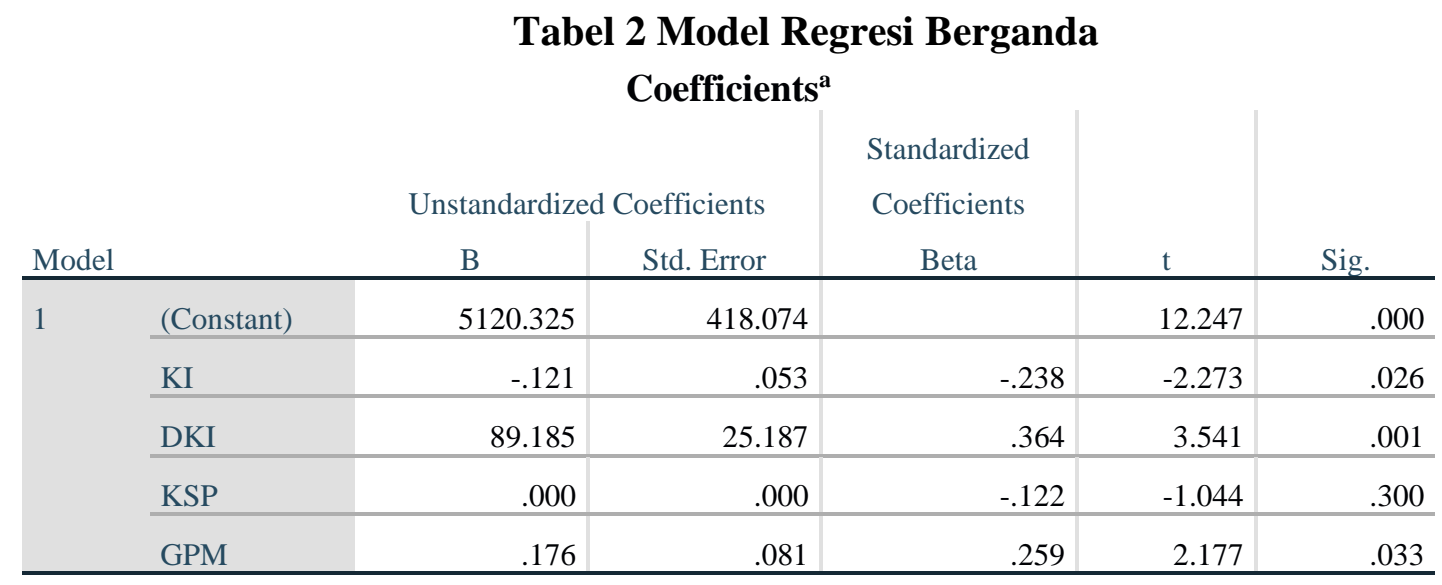

a. Dependent Variabel: CSR

Keterangan: KI (Kepemilikan Institusional), DKI (Dewan Komisaris Independen), KSP (Kepemilikan Saham Publik), dan GPM (Gross Profit Margin).

Hasil analisis data diatas berupa regresi linear berganda dapat diketahui bahwa model persamaan regresi sebagai berikut

\section{CSRDI $=5.120,325-0,121 \mathrm{KI}+89,185 \mathrm{DKI}+0,00 \mathrm{KSP}+0,176 \mathrm{GPM}+\dot{\varepsilon}$}

\section{Hasil Uji Hipotesis Pertama}

Hipotesis pertama untuk menguji apakah kepemilikan institusional berpengaruh positif terhadap pengungkapan CSR. dari tabel 1 diketahui bahwa tingkat singnifikan kepemilikan institusional sebesar 0,26 dengan arah negatif sehingga hipotesis pertama menerima H0 sehingga dapat disimpulkan bahwa kepemilikan institusional tidak dapat menambah pengungkapan CSR. sehingga hipotesis pertama ditolak

\section{Hasil Uji Hipotesis Kedua}

Selanjutnya untuk menguji apakah pengaruh positif dewan komisaris terhadap CSR, jika dilihat dari hasil olah data ditabel 1 dimana tingkat signifikan 0,01 dengan arah positif, dimana angka ini lebih kecil dari 0,05, menurut angka tersebut dapat dilihat bahwa dewan komisaris independen berpengaruh positif terhadap pengungkapan CSR, sehingga hipotesis kedua diterima. 


\section{Hasil Uji Hipotesis Ketiga}

Dalam pengujian ini dilihat pengaruh positif kepemilikan saham publik terhadap pengungkapan CSR, Adapun hal tersebut memperlihatkan di tabel 1 dimana tingkat signifikan uji hipotesis ini sebesar 0,00 dengan dibawah dari 0,05 dengan arah negatif, sehingga hal tersebut menggambarkan bahwa kepemilikan saham publik tidak bisa menambah pengungkapan CSR, sehingga hipotesis ketiga ditolak

\section{Hasil Uji Hipotesis Keempat}

Hipotesis keempat yang diuji dalam riset ini melihat profitabilitas dapat mempengaruhi pengungkapan CSR secara positif, dari hasil analisis dapat dilihat bahwa tingkat signifikan sebesar 0,033 dapat diketahui bahwa angka dibawah 0,05 dengan demikian hal ini mengambarkan bahwa profitabilitas dapat menambah pengungkapan CSR sehingga Hipotesis keempat diterima

\section{Uji Koefisien Determinasi}

Tabel 3 Koefesien Determinasi

\begin{tabular}{ll|c|c|c}
\hline \multicolumn{4}{c}{} & \multicolumn{4}{c}{ Model Summary } \\
Model & $\mathrm{R}$ & R Square & Adjusted R Square & Std. Error of the Estimate \\
\hline 1 & $.514^{\mathrm{a}}$ & .264 & .223 & 1458.84347 \\
\hline
\end{tabular}

a. Predictors: (Constant), GPM, DKI, KI, KSP

Keterangan: KI (Kepemilikan Institusional), DKI (Dewan Komisaris Independen), KSP (Kepemilikan Saham Publik), dan GPM (Gross Profit Margin).

Hasil analisis data diperoleh besarnya variabel independen yaitu kepemilikan institusional, dewan komisaris independen, kepemilikan saham publik terhadap CSR diperoleh R Square sejumlah 0,264. Riset ini dapat menunjukan variable bebas dapat mempengaruhi variable terikat senilai $26 \%$ secara bersamaan. Adapun factor yang tidak ada dalam penelitian menentukan presentasi sisanya yang tidak termasuk diteliti

\section{Uji Ketepatan Model (Uji F)}

\section{Tabel 4 Hasil Uji F}

\begin{tabular}{llr|r|r|r|r}
\multicolumn{7}{c}{ ANOVA $^{\text {a }}$} \\
Model & & Sum of Squares & df & Mean Square & F & Sig. \\
\hline 1 & Regression & 55670822.950 & 4 & 13917705.738 & 6.540 & $.000^{\mathrm{b}}$ \\
\cline { 2 - 7 } & Residual & 155360371.729 & 73 & 2128224.270 & & \\
\cline { 2 - 7 } & Total & 211031194.679 & 77 & & & \\
\hline
\end{tabular}

\footnotetext{
a. Dependent Variabel: CSR

b. Predictors: (Constant), GPM, DKI, KI, KSP

Keterangan: KI (Kepemilikan Institusional), DKI (Dewan Komisaris Independen), KSP (Kepemilikan Saham Publik), dan GPM (Gross Profit Margin).
} 
Uji koefesien simultan dipergunakan agar dapat diperlihatkan Apakah dalam pengembangan model regresi jika disertakan variable independen dapat memberikan pengaruh kepada variable dependen selaku bersamaan Adapun perhitungan ANOVA pada tabel 4 diketahui bahwa hasil uji variabel independent Bersama-sama pada variabel dependen dalam penelitian dengan uji $\mathrm{F}$. diperoleh tingkat signifikan 0,00 dengan demikian terdapat pengaruh signifikan secara bersamaan dengan CSR

\section{Pembahasan}

\section{Pengaruh Kepemilikan Institusi terhadap pengungkapan CSR}

Hasil uji hipotesis menunjukan pengaruh negatif signifikan kepemilikan institusional terhadap pengungkapan CSR sehingga hipotesis satu tidak dapat didukung hal ini ternyata menimbulkan ketidakkonsistenan dengan penelitian sebelumnya bahwa dinegara berkembang menunjukan hubungan positif signifikan terhadap pengungkapan CSR (Oh et al., 2011)(Saleh et al., 2010). Kepemilikan institusi lebih memilih untuk menaikan harga saham sehingga perhatian mereka kurang terhadap pengungkapan sosial Priandita (2011).

Hal ini juga dimungkinkan karena dimana kepemilikan institusional bukan hanya meliputi kepemilikan presentase saham saja tetapi juga meliputi reksadana dan dana pensiun dan juga melibatkan perusahaan keuangan sehingga terbagi menjadi kepemilikan instutisional perusahaan yang mewakili institusional kelompok perusahaan ataupun kelompok pemerintah dimana dinegara berkembang memiliki perusahaan yang banyak didominasi dengan keluarga atau pemegang saham pengendali ataupun substansial adalah hal yang biasa diterapkan. Dengan demikian pengaruh investor institusional bersifat sekunder dan hampir tidak ada (Khan et al., 2013)(Khandkk., 2013; Reed, 2002) (El-Bassiouny \& El-Bassiouny, 2019).

\section{Pengaruh Dewan Komisaris Independen terhadap pengungkapan CSR}

Hasil uji hipotesis menunjukan kepemilikan saham publik memiliki pengaruh positif terhadap pengungkapan CSR, hal ini sesuai riset Santioso dan Erline (2012) Hussainey dan Stapleton, 2012; (Veronica Siregar \& Bachtiar, 2010)(Haji, 2013), dimana komisaris yang berasal dari luar perusahaan memiliki pandangan yang lebih objektif dibandingkan dengan komposisi dewan yang berasal dari dalam perusahaan, hal ini dapat mendorong perusahaan untuk lebih mengungkapkan aktivitas yang dapat menambah keseimbangan keberadaan mereka dengan turut mengawasi keseimbangan kepentingan stakeholder Siregar (2016).

\section{Pengaruh Kepemilikan Saham Publik terhadap pengungkapan CSR}

Hasil uji hipotesis dapat menunjukan bahwa kepemilikan saham publik tidak berpengaruh terhadap pengungkapan CSR. Kepemilikan Saham Publik tidak dapat 
mempengaruhi Tingkat Pengungkapan Corporate Sosial Responsibility, temuan ini dapat dijelaskan bahwa kemungkinan kepemilikan saham publik diperusahaan Indonesia secara general belum mengarah pada perhatian terhadap isu permasalahan lingkungan dan sosial sebagai masalah penting yang secara terus menerus disajikan dalam penyajian annual report (Rahma \& Indah 2010). Selain itu dalam riset ditemukan bahwa Kepemilikan Saham Publik berpengaruh negatif terhadap Tingkat Pengungkapan Corporate Sosial Responsibility, dengan penjelasan jumlah kepemilikan saham publik yang tinggi, berdampak pada semakin berkurangnya level Pengungkapan Corporate Sosial Responsibility (Indraswari \& Astika (2015).

\section{Pengaruh Profitabilitas terhadap pengungkapan CSR}

Hasil uji hipotesis keempat menunjukan bahwa profitabilitas berpengaruh terhadap pengungkapan CSR. semakin tinggi kemampuan perusahaan menghasilkan laba akan berdampak terhadap kemampuan perusahaan untuk memberi pengaruh baik dari lingkungan untuk upaya penerapan penerapan CSR (Purba \& Yadnya, 2015) sehingga dapat diambil suatu analisis bahwa perusahaan yang telah berkinerja baik ditandai dengan kemampuan perusahaan dalam menghasilkan laba telah mendapatkan kepercayaan masyarakat sehingga upaya perusahaan dalam menjual produk mendapat sambuatan baik dari masyarakat sehingga menyebabkan produk tersebut laku dipasaran sehingga dapat meningkatkan profitabilitas perusahaan. Hal ini dapat dipergunakan untuk mengalokasikan Sebagian dana untuk kegiatan CSR semakin tinggi. Profitabilitas yang tinggi juga dapat memberikan peluang bagi pihak manajemen untuk mengungkapkan kegiatan CSR (Budiman, 2015)

\section{KESIMPULAN DAN SARAN}

\section{Kesimpulan}

Hasil penelitian dapat disimpulkan yang pertama bahwa kepemilikan institusional tidak berpengaruh signifikan terhadap pengungkapan CSR hal ini dikarenakan kepemilikan institusi beberapa didominasi oleh keluarga atau pemegang saham pengendali yang pada akhirnya mereka bersifat sekunder dan pengaruh mereka hampir tidak ada (Khan et al., 2013). Kepemilikan institusional tidak berpengaruh terhadap pengungkapan sosial juga dikarenakan mereka kurang mementingkan aktivitas sosial termasuk kegiatan pengungkapan sosial dan mereka cenderung mementingkan peningkatan harga saham. Kesimpulan yang kedua Dewan komisaris independen berpengaruh positif terhadap pengungkapan CSR (Hussainey dan Stapleton 2012), hal ini disebabkan karena dewan komisaris yang berasal dari luar institusi perusahaan akan bersifat objektif dimana mereka akan menjaga kepentingan 
stakeholder diantaranya adalah untuk menjaga keseimbangan aktivitas sosial, mereka juga mendukung aktivitas perusahaan agar dapat berlangsung sesuai dengan ketentuan dan mengawasi setiap aktivitas untuk mengontrol kecurangan sehingga setiap kepentingan organisasi maupun pihak-pihak lain terjaga dengan baik.

Kesimpulan yang ketiga menghasilkan kepemilikan saham publik tidak berpengaruh terhadap pengungkapan CSR hal ini disebabkan karena kurangnya kesadaran publik terutama investor terhadap pengungkapan aktivitas sosial, mereka lebih mementingkan kenaikan investasi yang ditandai dengan naiknya jumlah saham. Kesimpulan yang keempat yaitu profitabilitas berpengaruh positif terhadap pengunggkapan CSR hal ini dapat dapat ditandai dengan kemampuan perusahaan dalam menghasilkan laba, maka perusahaan akan mengalokasikan Sebagian dari labanya untuk disisihkan agar dapat melaksanakan kegiatan sosial yang pada akhirnya akan menaikan kepercayaan masyarakat terhadap produk yang dijual perusahaan.

Saran untuk penelitian selanjutnya diharapkan pengambilan sampel dalam penelitian ini yang hanya 78 sampel sehingga hal ini menimbulkan hasil penelitian tidak dapat digeneralisir dengan baik.

\section{DAFTAR PUSTAKA}

Chau, G., \& Gray, S. J. (2010). Family ownership, board independence and voluntary disclosure: Evidence from Hong Kong. Journal of International Accounting, Auditing and Taxation, 19(2), 93-109. https://doi.org/10.1016/j.intaccaudtax.2010.07.002

Damayanty, P., \& Djaddang, S. (2020). Analysis on the role of corporate social responsibility on company fundamental factor toward stock return (study on retail industry registered in indonesia stock exchange. 22(1), 34-43.

Damayanty, P., \& Putri, T. (2021). The Effect of Corporate Governance on Tax Avoidance by Company Size as The Moderating Variable. https://doi.org/10.4108/eai.14-92020.2304404

Dartey-Baah, K., \& Amponsah-Tawiah, K. (2011). Exploring the limits of Western Corporate Social Responsibility Theories in Africa. International Journal of Business and Social Sciences, 2(18), 126-137.

El-Bassiouny, D., \& El-Bassiouny, N. (2019). Diversity, corporate governance and CSR reporting: A comparative analysis between top-listed firms in Egypt, Germany and the USA. Management of Environmental Quality: An International Journal, 30(1), 116136. https://doi.org/10.1108/MEQ-12-2017-0150

Ezat, A., \& El-Masry, A. (2008). The impact of corporate governance on the timeliness of corporate internet reporting by Egyptian listed companies. Managerial Finance, 34(12), 848-867. https://doi.org/10.1108/03074350810915815

Fontaine, M. (2013). Corporate Social Responsibility and Sustainability: The New Bottom Line? National Louis University. International Journal of Business and Social Science, 4(4), 110-119. www.ijbssnet.com 
Hidayat, T. (2017). Pengaruh Pengungkapan Corporate Social Responsibility Dan Struktur Kepemilikan Terhadap Praktik Penghindaran Pajak. Emerging Infectious Diseases, 4(1), 1-7. http://www.mendeley.com/research/geology-volcanic-history-eruptive-styleyakedake-volcano-group-central-

japan/\%0Ahttps://doi.org/10.1016/j.actatropica.2019.02.002\%0Ahttps://doi.org/10.1016/ j.actatropica.2018.07.028\%0Ahttp://dx.doi.org/10.1016/j.ijppaw.201

Jii, T. (2015). Pengaruh Profitabilitas Dan Mekanisme Corporate Governance Terhadap Pengungkapan Csr Perusahaan Terdaftar Jii 2011-2013. Accounting Analysis Journal, 4(1), 1-12. https://doi.org/10.15294/aaj.v4i1.7829

Khan, A., Muttakin, M. B., \& Siddiqui, J. (2013). Corporate Governance and Corporate Social Responsibility Disclosures: Evidence from an Emerging Economy. Journal of Business Ethics, 114(2), 207-223. https://doi.org/10.1007/s10551-012-1336-0

Komang. (1975). PENGARUH STRUKTUR KEPEMILIKAN SAHAM DAN CORPORATE SOCIAL RESPONSIBILITY PADA NILAI PERUSAHAAN. XVIII(2), 49-58.

Kristi, A. A. (2013). Faktor-Faktor Yang Mempengaruhi Pengungkapan Corporate Social Responsibility pada Perusahaan Publik Di Indonesia. Fakultas Ekonomi Dan Bisnis Universitas Brawijaya, Volume 53(9), 1-27.

Li, W., \& Zhang, R. (2010). Corporate Social Responsibility, Ownership Structure, and Political Interference: Evidence from China. Journal of Business Ethics, 96(4), 631-645. https://doi.org/10.1007/s10551-010-0488-z

Maqbool, S., \& Zameer, M. N. (2018). Corporate social responsibility and financial performance: An empirical analysis of Indian banks. Future Business Journal, 4(1), 8493. https://doi.org/10.1016/j.fbj.2017.12.002

Mayasari, ariyani anggi. (2021). Good Corporate Governance Dan Kinerja. 2(2), 135-144.

Mayasari, \& Al-musfiroh, H. (2020). Pengaruh Corporate Governance, Profitabilitas, Ukuran Penghindaran Pajak Pada Perusahaan Manufaktur Pada Tahun 2014. Jurnal Akuntansi Dan Bisnis Indonesia, 1(2), 83-92.

Oh, W. Y., Chang, Y. K., \& Martynov, A. (2011). The Effect of Ownership Structure on Corporate Social Responsibility: Empirical Evidence from Korea. Journal of Business Ethics, 104(2), 283-297. https://doi.org/10.1007/s10551-011-0912-z

Purba, I., \& Yadnya, I. (2015). Pengaruh Ukuran Perusahaan Dan Leverage Terhadap Profitabilitas Dan Pengungkapan Corporate Social Responsibility. E-Jurnal Manajemen Universitas Udayana, 4(8), 243261.

Pyo, G., \& Lee, H. Y. (2013). The association between corporate social responsibility activities and earnings quality: Evidence from donations and voluntary issuance of CSR reports. Journal of Applied Business Research, 29(3), 945-962. https://doi.org/10.19030/jabr.v29i3.7793

Rindawati, M., \& Asyik, N. (2013). Pengaruh Profitabilitas, Ukuran Perusahaan, Leverage, dan Kepemilikan Publik Terhadap Pengungkapan Corporate Social Responsibility (CSR). Jurnal Ilmu \& Riset Akuntansi, 4(6), 2-5.

Rita, M. R., \& Sartika. (2012). Pengaruh Profitabilitas Dan Kepemilikan Saham Publik Terhadap Luas Pengungkapan Corporate Social Responsibility (Csr). Jurnal Riset Bisnis Indonesia, 9(2), 141-152.

Saleh, M., Zulkifli, N., \& Muhamad, R. (2010). Corporate social responsibility disclosure and its relation on institutional ownership: Evidence from public listed companies in Malaysia. Managerial Auditing Journal, 25(6), 591-613. https://doi.org/10.1108/02686901011054881

Samaha, K., Dahawy, K., Hussainey, K., \& Stapleton, P. (2012). The extent of corporate 
governance disclosure and its determinants in a developing market: The case of Egypt. Advances in Accounting, 28(1), 168-178. https://doi.org/10.1016/j.adiac.2011.12.001

Sandy, M. K., Paseleng, M. C., \& Mayopu, R. G. (2020). Pengaruh Efektivitas Corporate Social Responsibility (Csr) Pada Aspek Environmenal Sustainability Terhadap Reputasi Perusahaan Grand Hyatt Bali (Pt Wyncor Bali). Jurnal Signal, 8(1), 1. https://doi.org/10.33603/signal.v8i1.2533

Veronica Siregar, S., \& Bachtiar, Y. (2010). Corporate social reporting: empirical evidence from Indonesia Stock Exchange. International Journal of Islamic and Middle Eastern Finance and Management, 3(3), 241-252. https://doi.org/10.1108/17538391011072435

Wahba, H., \& Elsayed, K. (2015). The mediating effect of financial performance on the relationship between social responsibility and ownership structure. Future Business Journal, 1(1-2), 1-12. https://doi.org/10.1016/j.fbj.2015.02.001

Widjanarko, \& Nurmelia, S. (2020). Operasi Terhadap Kebijakan Dividend Pada Perusahaan. Jurnal Akuntansi Dan Bisnis Indonesia, 1(2), 50-63. 